\title{
CONSUMO ENERGÉTICO E PATINAGEM DE UM TRATOR AGRÍCOLA TRACIONANDO UMA ENXADA ROTATIVA E UM ARADO DE DISCOS
}

\author{
Diego Sichocki ${ }^{1}$, Renato Adriane Alves Ruas ${ }^{2}$, Luciel Rauni Dezordi ${ }^{3}$, Leonardo Fideles Caixeta ${ }^{4}$, Bruno Monteiro \\ Silva ${ }^{5}$.
}

\section{RESUMO}

Parte da energia gerada pelos tratores agrícolas é perdida quando ocorre patinagem. Para a melhoria da eficiência de tração pode-se utilizar alguns componentes mecânicos do trator, como o bloqueio do diferencial e a tração dianteira auxiliar, quando presente. Em comparação com tratores do mesmo modelo que possuem TDA com os que não a possuem, verifica-se aumento de 33\% na força de tração e redução dos índices de patinagem, mantendo-se o consumo energético igual entre os dois tratores. Objetivou-se com este trabalho, avaliar o efeito da utilização da tração dianteira auxiliar (TDA), e do bloqueio do diferencial na patinagem e no consumo de combustível de um trator agrícola, operando com dois tipos de implementos de preparo do solo. Utilizou-se o delineamento inteiramente casualizado em esquema fatorial $2 \times 2 \times 2$, sendo: dois equipamentos (enxada rotativa e arado de discos); tração dianteira auxiliar acionada ou não e bloqueio do diferencial acionado ou não, com quatro repetições. Para avaliar o índice de patinagem, utilizou-se um contador de batidas analógico. O consumo de combustível do motor do trator foi mensurado com um fluxômetro. Os dados obtidos foram submetidos ao teste de Tukey a 5\% de significância. A patinagem foi maior com o arado de discos e o consumo de combustível, maior com a enxada rotativa em uso. O acionamento da tração dianteira auxiliar reduziu a patinagem quando o equipamento tracionado foi a enxada rotativa. O bloqueio e tração dianteira auxiliar não reduziram os índices de patinagem, mas influenciaram negativamente o consumo de combustível.

Palavras-chave: bloqueio do diferencial, perdas de potência, preparo do solo, tração dianteira auxiliar

\section{ABSTRACT \\ ENERGY CONSUMPTION AND SLIPPAGE OF AGRICULTURAL TRACTOR PULLING A ROTARY TILLER AND DISK PLOUGH}

Part of the energy generated by tractors is lost when slippage occurs. To improve the efficiency of traction certain mechanical components of the tractor may be used, such as the differential lock and front wheel assist, when present. When comparing tractors of the same model with and without TDA, there is a $33 \%$ increase in traction force and reduced slippage index, maintaining the same energy consumption between the two tractors. The objective of this study was to evaluate the effect of the use of front wheel assist and differential lock on the slippage and fuel consumption of a tractor based on two types of soil preparation. A completely randomized design was used with $2 \times 2 \times 2$ factorial, consisting of: two equipment (rotary tilling and disc plowing), with or without front wheel assist activated and with or without the differential lock activated, along with four replications. To evaluate the level of slippage, an analog beat counter was used. Data was collected over a distance of $50 \mathrm{~m}$ with the tractor operating in the different experimental modes. Fuel consumption of the tractor was measured with a flowmeter. The obtained data was submitted to the Tukey test at 5\% significance. Slippage was greater when disc plowing and fuel consumption was greater in the case of rotary tilling. Front wheel assists reduced slippage when using rotary tilling. The differential lock and front wheel assist did not reduce the rate of slippage, but negatively influenced fuel consumption.

Keywords: differential lock, power losses, soil preparation, front wheel assist

\section{Recebido para publicação em 13/12/2012. Aprovado em 26/06/2013.}

1 - Eng. Agrônomo. Mestrando em Produção Vegetal/ UFV - Campus Rio Paranaíba, E-mail: diegosichocki@hotmail.com

2 - Eng. Agrônomo. Professor Adjunto II Mecanização Agrícola/ UFV - Campus Rio Paranaíba, E-mail: renatoruas@ufv.br

3 - Eng. Agrônomo. Mestrando em Produção Vegetal/UFV - Campus Rio Paranaíba, E-mail: luciel.dezordi@gmail.com

4 - Graduando em Agronomia/ UFV - Campus Rio Paranaíba, E-mail: Leonardo.caixeta@ufv.br

5 - Graduando em Agronomia/ UFV - Campus Rio Paranaíba, E-mail: bruno.monteiro@ufv.br 


\section{INTRODUÇ̃̃O}

Para se obter um preparo de solo que proporcione condições adequadas para o desenvolvimento das raízes das plantas, sobre tudo aquelas mais exigentes, é necessário lançar mão do uso de implementos que normalmente demandam elevado consumo de combustível devido ao grande volume de solo mobilizado (REICHERT et al., 2007, STRECK et al., 2004). Dentre esses, destacam-se $\mathrm{o}$ arado de discos e a enxada rotativa, equipamentos que exigem do trator elevada capacidade trativa (SALVADOR et al., 2008). Comumente, nessas operações, o trator está sujeito à ocorrência de maior patinagem e variações de consumo de combustível e de velocidade de deslocamento em virtude das rigorosas condições de trabalho às quais é submetido.

Segundo Bowers (1978), a patinagem é necessária para evitar o desgaste ou quebra da transmissão do trator agrícola, sendo limites aceitáveis entre 10 e $15 \%$ em solos firmes. Entretanto, quando estes índices são superados, ocorrem perdas de eficiência tratória e acentua-se o desgaste dos pneus, uma vez que o desgaste dos pneus aumenta de forma quadrática em função do índice de patinagem (BARBOSA et al., 1998).

Para a melhoria da eficiência de tração, pode-se utilizar alguns componentes mecânicos do trator como o bloqueio do diferencial e a tração dianteira auxiliar (TDA), quando presente. Comparando-se tratores do mesmo modelo que possuem TDA com os que não a possuem, verifica-se aumento de $33 \%$ na força de tração e redução dos índices de patinagem, mantendose o consumo energético igual entre os dois tratores (YANAI et al., 1999). O mesmo acontece com o uso do bloqueio do diferencial, uma vez que as duas rodas deslocam-se na mesma velocidade, mesmo quando uma delas passar sobre um terreno que tenha menor aderência (MACHADO et al., 2010).

O consumo de combustível varia em função de cada equipamento utilizado, da condição do solo e marcha em que o trator trabalha. A operação de preparo do solo com arado de discos, de acordo com Salvador et al. (2008), requer consumo específico maior quando comparado a grades e escarificadores. Já a enxada rotativa, comparada, ao arado de discos, em geral, exige menor consumo específico de combustível (KHEIRALLA et al. 2004).
Acredita-se que o uso simultâneo da TDA e do bloqueio do diferencial em locais não cultivados em curvas de nível possa trazer vantagens quanto ao aumento da eficiência tratória e à redução do consumo de combustível na operação do trator agrícola, tanto com o arado como com a enxada rotativa. Essas informações são muito importantes para o adequado dimensionamento e uso desses equipamentos. Assim, objetivou-se com este trabalho, avaliar o desempenho de um trator New Holland TL 85, variando dois tipos de equipamentos e o acionamento do bloqueio do diferencial e da TDA no consumo de combustível e no índice de patinagem do conjunto mecanizado.

\section{MATERIAL E MÉTODOS}

O ensaio foi realizado no campo Experimental da Universidade Federal de Viçosa - Campus Rio Paranaíba. O trator utilizado foi o TL 85 New Holland, com potência de $61,6 \mathrm{~kW}(83 \mathrm{cv})$ no motor, provido de tração dianteira auxiliar (TDA), equipado com pneus diagonais com as seguintes dimensões: 14.9-24 na dianteira e 18.4-30 na traseira, preenchidos com água até $75 \%$ do seu volume interno. A pressão de insuflagem durante o ensaio foi de $151,6 \mathrm{kPa}$ para os pneus dianteiros e $124,1 \mathrm{kPa}$ para os traseiros. Durante os ensaios o trator operou a $1800 \mathrm{rpm}$ na marcha II-2, que proporcionou velocidade de $2,4 \mathrm{~km} \mathrm{~h}^{-1}$.

Utilizou-se o delineamento em blocos casualizados em esquema fatorial $2 \times 2 \times 2$, com quatro repetições. Os tratamentos constaram de: dois equipamentos; (enxada rotativa e arado de discos); TDA acionada e não acionada; bloqueio acionado e não acionado. Foram feitas avaliações de consumo de combustível, velocidade de deslocamento e índice de patinagem. A enxada rotativa utilizada foi a do tipo montada, modelo ER 200 B marca Mec$\mathrm{Rul}^{\circledR}$, com conjunto de 48 lâminas acionadas pela tomada de potência, largura de ataque de $2,0 \mathrm{~m}$, massa de $565 \mathrm{~kg}$ e demanda de potência estimada na TDP pelo fabricante de $53,2 \mathrm{~kW}$. O arado de discos modelo foi um modelo AF marca Baldan ${ }^{\circledR}$, também montado, que possui três discos de 28 polegadas, não reversíveis, massa de $402 \mathrm{~kg}$ e demanda de potência estimada pelo fabricante de $53 \mathrm{~kW}$. Os equipamentos foram regulados para trabalharem a

\section{REVENG} 441-446p.

ENGENHARIA NA AGRICULTURA, VIÇOSA - MG, V.21 N.5, SETEMBRO / OUTUBRO 2013 
uma profundidade de $0,20 \mathrm{~m}$.

Para se mensurar o índice de patinagem, foram fixadas, em quatro parafusos de cada roda motriz do trator, hastes metálicas que, por impacto, registravam em um contador de batidas analógico o número de voltas de cada roda. Para a tomada de dados com o arado, o trator trafegou sobre solo em condição de pousio, com vegetação predominantemente formada por capim braquiária. Quando utilizou-se a enxada rotativa, o trator trafegou sobre solo arado na operação anterior. Essa condição imposta no trabalho para a enxada rotativa é devido às condições reias de campo enfrentado nas propriedades da região da realização do trabalho.

As condições iniciais de preparo de solo foram distintas, pois a enxada exige um preparo prévio do solo para que não ocorra esforço extremo em seus elementos ativos (lâminas), com desgaste prematuro ou até mesmo quebra. $\mathrm{O}$ arado pode ser utilizado em solo mantido em pousio sem que ocorra desgaste ou esforço excessivo de seus elementos ativos. O mesmo método foi adotado por Kheiralla et al. (2004), que avaliaram o arado de discos em solo não revolvido e enxada rotativa em solo que previamente foi preparado com arado de aivecas.

A tomada dos dados com a enxada rotativa foi feita imediatamente após a coleta dos dados do arado de discos. O solo da área em que foi realizado o experimento é de textura areno-argilosa, e no momento do ensaio se encontrava com índice de umidade de $29 \%$.

O cálculo do índice de patinagem foi feito de acordo com a Equação 01.

$P(\%)=\frac{d_{0}-d_{1}}{d_{0}} * 100$

em que,

$P=$ patinagem;

$d_{0=\text { Distância percorrida pelas rodas no solo com }}$ o trator sem carga;

$d_{1}=$ Distância percorrida pelas rodas no solo com o trator com carga.
A distância percorrida pela roda foi calculada em função do número de voltas registradas no contador de batidas e multiplicada pelo perímetro do pneu do trator. O consumo de combustível foi mensurado utilizando um fluxômetro, construído para o desenvolvimento deste trabalho. Tratase de uma proveta graduada preenchida com combustível com uma saída na parte inferior para a admissão da bomba injetora e uma mangueira de entrada pela parte superior que constituía o retorno da bomba. Dessa forma, apesar do trator estar em funcionamento, lia-se apenas o consumo, uma vez que o retorno era depositado na proveta.

Cada parcela experimental era composta por $50 \mathrm{~m}$ de comprimento, com um metro de largura para o arado e dois metros para a enxada rotativa, em virtude da largura de trabalho de cada equipamento. Para a coleta dos dados, o trator percorria a distância de $50 \mathrm{~m}$ e, antes de sua partida e ao final da parcela, se tomavam os dados registrados nos contadores de batida de cada roda e do fluxômetro. Media-se também o tempo para percorrer esse espaço com o auxílio de um cronômetro. Com os valores de tempo gasto para se percorrer os $50 \mathrm{~m}$ da parcela experimental, foi determinada a velocidade de trabalho.

Os dados do experimento foram submetidos à análise de normalidade pelo Teste de ShapiroWilk. Observada a normalidade, os dados foram submetidos à análise de variância e quando significativos, as médias foram comparadas pelo teste de Tukey a 5\% de significância. Utilizou-se o Software SAEG 9.1 para processamento dos dados.

\section{RESULTADOS E DISCUSSÃO}

A análise de variância (Anova) demonstrou não haver interação significativa entre o uso da tração dianteira auxiliar e do bloqueio do diferencial com o acoplamento dos diferentes equipamentos. Houve diferença significativa para o índice de patinagem e para o consumo de combustível quando se comparou os dois tipos de equipamentos tracionados pelo trator (Quadro 1).

$\mathrm{O}$ índice de patinagem das rodas motrizes do trator foi maior quando o trator tracionou o arado de discos $(18,13 \%)$, em relação à enxada rotativa $(15,4 \%)$, sendo os valores obtidos pela enxada 
Quadro 1. Consumo de combustível e Índice de Patinagem de um trator tracionando enxada rotativa e arado de discos

\begin{tabular}{lcc}
\hline Implemento & Consumo $\left(\mathrm{kg} \mathrm{kW} \mathrm{h}^{-1}\right)$ & Índice de Patinagem (\%) \\
\hline Arado de discos & $0,11 \mathrm{~b}$ & $18,13 \mathrm{a}$ \\
Enxada Rotativa & $0,13 \mathrm{a}$ & $15,4 \mathrm{~b}$ \\
\hline $\mathrm{CV} \%$ & 2,79 & 16 \\
\hline
\end{tabular}

Médias seguidas de letras iguais não diferem entre si pelo teste de Tukey $(\mathrm{p}<0,05)$.

pouco acima dos $15 \%$ aceitáveis (BOWERS, 1978). O menor índice de patinagem desenvolvido pelo trator, quando tracionado o equipamento, foi da enxada rotativa, resultado explicado por Shibusawa (1993). Segundo este autor, quando as lâminas do eixo rotativo da enxada acionadas pela TDP tocam o solo e giram no mesmo sentido de deslocamento do trator, proporcionam somatório de forças responsáveis por romperem as forças contrárias ao deslocamento do trator. Já com relação ao arado de discos, ocorre maior resistência devido aos seus elementos ativos serem posicionados com angulação perpendicular àquela do deslocamento do trator em regime de trabalho (MELlO; MAGALHÃES, 1995). Com o índice de patinagem desenvolvido pelo trator quando tracionou o arado, sugere-se perda de eficiência tratória por parte do veículo, pois, segundo Bowers (1978), valores de patinagem acima de 15\% prejudicam a eficiência de tração do trator.

O consumo de combustível proporcionado pelo trator ao tracionar o arado de discos foi menor em relação ao tracionamento da enxada rotativa. Rodrigues et al. (2006) comprovaram que, ao passo que aumentava o índice de patinagem das rodas motrizes de um microtrator, o consumo de combustível era reduzido em função desse aumento de patinagem. Opondo-se a estes resultados, os resultados deste trabalho demonstraram que o aumento do índice de patinagem, quando se tracionou o arado, não foi acompanhado pelo aumento no consumo de combustível, ocorrendo o oposto para a enxada rotativa. Kheiralla et al. (2004), quando testaram vários implementos para o preparo de solo, observaram que a enxada rotativa requeria menor consumo energético que o arado de discos, opondo-se aos resultados aqui encontrados.

Comumente, a utilização da enxada rotativa ocorre após o preparo do solo com mais de duas operações de gradagem ou aração e, nessas condições, o solo já se encontra mais pulverizado, exigindo menor esforço por parte da enxada rotativa. Nesse trabalho, a operação com enxada rotativa foi feita após apenas uma operação com arado de discos, elevando a demanda de potência na TDP para a realização do preparo do solo e aumentando o consumo de combustível. Salokhe e Ramalingam (2003) observaram que, quando feita apenas uma passada de enxada rotativa, ocorria maior consumo energético comparado a terceira passagem com a enxada rotativa na mesma área. Souza et al. (2001), avaliando a demanda energética para o acionamento de uma colhedora de feijão acoplada a um trator agrícola, constataram que apenas 14,8\% da potência do trator foi usada para tracionar a colhedora, sendo o restante da potência disponível empregada para acionar seus mecanismos internos. Esse resultado pode justificar o maior consumo de combustível quando o equipamento acoplado era a enxada rotativa, que exige maior parte da potência para acionar o conjunto de facas rotativas.

Com o uso do bloqueio do diferencial e da tração dianteira auxiliar, variando os tipos de equipamentos tracionados pelo trator, não houve interação significativa entre estes fatores nas variáveis consumo de combustível e velocidade de deslocamento, mas observou-se interação significativa para o índice de patinagem, conforme o Quadro 2.

Com o acionamento do bloqueio do diferencial, houve influência nos índices de patinagem pelo trator apenas quando se utilizou o arado de discos. Entretanto, ao se acionar o bloqueio do diferencial na comparação entre os equipamentos avaliados, em condições de trabalho, a patinagem foi menor com a enxada rotativa. $\mathrm{O}$ melhor desempenho tratório foi observado na condição de bloqueio desligado, quando o equipamento foi acoplado à enxada

\section{REVENG}

$$
\text { 441-446p. }
$$

ENGENHARIA NA AGRICULTURA, VIÇOSA - MG, V.21 N.5, SETEMBRO / OUTUBRO 2013 
Quadro 2. Efeito do uso da enxada rotativa e do arado de discos com acionamento do bloqueio de diferencial e tração dianteira auxiliar nos índices de patinagem (\%) de um trator New Holland TL 85

\begin{tabular}{lcccc}
\hline & \multicolumn{2}{c}{ Bloqueio do Diferencial } & \multicolumn{2}{c}{ Tração dianteira auxiliar } \\
\cline { 2 - 5 } Implemento & Ligado & Desligado & Ligada & Desligada \\
\hline Arado de discos & $13,8 \mathrm{Ab}$ & $20,4 \mathrm{Aa}$ & $11,2 \mathrm{Bb}$ & $20,0 \mathrm{Aa}$ \\
Enxada Rotativa & $15,8 \mathrm{Aa}$ & $16,99 \mathrm{Ba}$ & $16,1 \mathrm{Ab}$ & $19,6 \mathrm{Aa}$ \\
\hline $\mathrm{CV}(\%)$ & 22 & 16 & 22 & 16 \\
\hline
\end{tabular}

Médias seguidas de letras iguais maiúsculas nas colunas e minúsculas nas linhas não diferem entre si pelo teste de Tukey $(\mathrm{p}<0,05)$.

rotativa, provavelmente pelo fato de a enxada proporcionar ao trator uma menor resistência de rolamento, uma vez que proporciona movimento das facas favorável ao sentido de deslocamento do trator (SHIBUSAWA, 1993). Observa-se ainda que, com a utilização de bloqueio do diferencial ao tracionar o arado, reduz-se os índices de patinagem a índices aceitáveis.

Verschoore e Duquesne (2001) afirmam que o bloqueio do diferencial proporciona ao trator melhor eficiência tratória. Pelo fato da menor aderência dos pneus no solo em que o trator se deslocou com a enxada rotativa, devido ao revolvimento anterior com o arado, provavelmente o uso desse componente mecânico justifica o melhor desempenho tratório.

O uso da tração dianteira auxiliar proporcionou diferenças nos índices de patinagem para o trator com o arado e enxada rotativa em regime de trabalho (Tabela 02). Como o conjunto trator-enxada se deslocou em solo revolvido anteriormente pelo conjunto trator-arado, houve resposta ao uso da TDA, em virtude da maior aderência ao solo mobilizado. Tratores que possuem tração dianteira auxiliar apresentam força de tração $33 \%$ maior que seu modelo sem esse componente mecânico, além de reduzir os índices de patinagem dos rodados (YANAI et al., 1999). O acionamento da TODA, na comparação entre os implementos, reduziu o índice de patinagem do trator com a utilização do arado. Quando as operações foram realizadas com a TODA acionada, menores índices de patinagem foram observados com o acoplamento do arado. A redução da patinagem com o uso da TDA para $\mathrm{o}$ arado pode ser explicada pelo fato da maior resistência ao rolamento proporcionado por este tipo de implemento. Os seus elementos ativos atacam o solo de forma perpendicular, e com isso aumentam a exigência de força na barra de tração, promovendo maior patinagem.

\section{CONCLUSÕES}

- O índice de patinagem foi maior com o uso do arado de discos e o consumo de combustível foi maior com a enxada rotativa;

- A tração dianteira auxiliar reduziu os índices de patinagem em ambos equipamentos que foram acoplados;

- O uso de bloqueio reduziu significativamente a patinagem quando o equipamento acoplado foi o arado de discos.

\section{REFERÊNCIAS BIBLIOGRÁFICAS}

BARBOSA, J.A. Análise de um modelo para predição de desgaste em pneus motrizes de tratores agrícolas. 1998.41f. Dissertação(Mestrado em Mecanização Agrícola) - Universidade Federal de Viçosa, Viçosa - MG, 1998.

BOWERS, W. Matching equipment to big tractors for efficient field-operations. In: ASAE INTERNATIONAL MEETING, 1978, Utah. Procedings... Logan: Utah State University, 1978. 8p.

KHEIRALLA, A.F.; YAHYA, A.; ZOHADIE, M.; ISHAK, W. Modelling of power and energy requirements for tillage implements operating in Serdang sandy clay loam, Malaysia. Soil \& Tillage Research, Amsterdam, v.78, p.21-34, 2004. 
MACHADO, A.L.T.; REIS, A.V.; MACHADO, R.L.T. Tratores para Agricultura Familiar: Guia de Referência. Pelotas: UFPEL, 2010. 125p.

MELLO, R.C.; MAGALHÃES, P.S.G. Desempenho Operacional de um Arado de Discos. Bragantia, Campinas, v.54, p.447-454, 1995.

REICHERT, J.M.; SUZUKI, L.E.A.S.; REINERT, D.J. Compactação do solo em sistemas agropecuários e florestais: identificação, efeitos, limites críticos e mitigação. In: CERETTA, C.A.; SILVA, L.S. da; REICHERT, J.M. (Org.). Tópicos em ciência do solo. Viçosa, Sociedade Brasileira de Ciência do Solo, 2007, p.49-134.

RODRIGUES, D.E.; TEIXEIRA, M.M.; FERNANDES, H.C.; MODOLO, J.A.; RODRIGUES, G.J. Desempenho de um micro trator utilizando-se motores com diferentes alternativas energéticas. Acta Scientiarun Technology, Maringá, v.28, p.55-63, 2006.

SALOKHE, V.M.; RALAMINGAM, N. Effect of rotation of a rotary tiller on draft and power requirements in a Bangkok clay soil. Journal of Terramechanics, Hannover, v.39, p.195-205, 2002.

SALVADOR, N.; BENEZ, S.H.; MION, R.L. Revista Ciência Agronômica, Fortaleza, v.39, n.3, p.378-384, 2008.
SOUZA, C.M.A.; QUEIROZ, D.M.; DIAS, G.P.; PINTO, F.A.C. Potência necessária para acionamento de uma colhedora de fluxo axial para feijão. Revista Brasileira de Engenharia Agrícola e Ambiental, Campina Grande, v.5, p.538-545, 2001.

SHIBUSAWA, S. Reverse-Rotational Rotary Tiller for Reduced Power Requirement in Deep Tillage. Journal of Terramechanics, Hannover, v.30, p.205-217, 1993.

STRECK, C.A.; REINERT, D.J.; REICHERT, J.M.; KAISER, D.R. Modificações em propriedades físicas com a compactação do solo causada pelo tráfego induzido de um trator em plantio direto. Ciência Rural, Santa Maria, v.34, p.755-760, 2004.

VERSCHOORE, R.; DUQUESNE, F. Simulation of influence of differential control on tractor work rate. Journal of Terramechanics, Hannover, v.38, p.221-233, 2001.

YANAI. K.; SILVEIRA, G.M.; LANÇAS, K.P.; CORREA, I.M.; MAZIERO, J.V.G. Desempenho operacional de trator com e sem acionamento da tração dianteira auxiliar. Pesquisa agropecuária Brasileira, Brasília, v.34, p.1427-1434, 1999. 